\title{
INFLUENCE OF SKY CONDITIONS ON ESTIMATION OF PHOTOSYNTHETIC PHOTON FLUX DENSITY FOR AGRICULTURAL ECOSYSTEM
}

\author{
M. Yamashita ${ }^{1}$ and M. Yoshimura ${ }^{2}$ \\ ${ }^{1}$ Tokyo University of Agriculture and Technology, Faculty of Agriculture, 3-5-8 Saiwai-cho, Fuchu, Tokyo, Japan - \\ meguyama@cc.tuat.ac.jp \\ ${ }^{2}$ PASCO Corporation, PASCO Research Institute, 2-8-10 Higashiyama, Meguro-ku, Tokyo, Japan - mairtu1698@pasco.co.jp
}

Commission III, WG III/10

KEY WORDS: PPFD, PAR, Solar radiation, PAR fraction, Quantum-to-energy ratio, Diffuse ratio, Clearness index, Sky conditions

\begin{abstract}
:
Photosynthetic photon flux density (PPFD: $\mu \mathrm{mol} \mathrm{m} \mathrm{m}^{-2} \mathrm{~s}^{-1}$ ) is indispensable for plant physiology processes in photosynthesis. However, PPFD is seldom measured, so that PPFD has been estimated by using solar radiation (SR: $\mathrm{W} \mathrm{m}^{-2}$ ) measured in world wide. In method using SR, there are two steps: first to estimate photosynthetically active radiation (PAR: $\mathrm{W} \mathrm{m}^{-2}$ ) by the fraction of PAR to SR (PF) and second: to convert PAR to PPFD using the ratio of quanta to energy $\left(Q / E: \mu\right.$ mol $\left.\mathrm{J}^{-1}\right)$. $P F$ and $Q / E$ usually have been used as the constant values, however, recent studies point out that $P F$ and $Q / E$ would not be constants under various sky conditions. In this study, we use the numeric data of sky-conditions factors such cloud cover, sun appearance/hiding and relative sky brightness derived from whole-sky image processing and examine the influences of sky-conditions factors on $P F$ and $Q / E$ of global and diffuse PAR. Furthermore, we discuss our results by comparing with the existing methods.
\end{abstract}

\section{INTRODUCTION}

Photosynthetically active radiation (PAR) from 400 to $700 \mathrm{~nm}$ included in solar radiation (SR: $\mathrm{W} \mathrm{m}^{-2}$ ) is the source of energy for photosynthesis. Terrestrial vegetation, especially the crops which have short lives, are influenced by SR under local weather in year by year. To predict precise agricultural products is one of the important issues since abnormal weather due to climate variability have been happened frequency. To understand crop growing and predict yields are required photosynthetic models using PAR data as input parameter. Furthermore, diffuse PAR is also required in addition to global PAR for accurate and detailed modeling of photosynthesis.

PAR can be expressed by two physical units of energy (irradiance: $\mathrm{W} \mathrm{m}^{-2}$ ) and quantum (photon flux density: $\mu \mathrm{mol} \mathrm{m}^{-2}$ $\left.\mathrm{s}^{-1}\right)$. In photosynthetic studies, PAR with quantum units, that is photosynthetic photon flux density (PPFD), is generally used in measurement and modeling for photosynthesis. However, PPFD is seldom measured, so that it has been estimated by using the fraction of PAR irradiance to SR (PAR fraction $(P F)$ : unitless) and then converted from PAR irradiance by multiplying the ratio

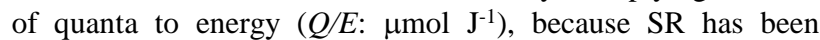
routinely observed at meteorological stations in worldwide (Ohmura et al., 1998). PAR fraction and $Q / E$ in PAR wavelength have usually been used as the constant values of 0.5 (unitless) and $4.57\left(\mu \mathrm{mol} \mathrm{J}{ }^{-1}\right)$ respectively (Monteith, 1977; McCree, 1972), that is to multiply about $2.3\left(\mu \mathrm{mol} \mathrm{J}{ }^{-1}\right)$ to SR. For this estimation method, several previous studies recently point out that $P F$ and $Q / E$ would not be constants under different local climate, weather and various sky conditions (Zhang et al., 2000; Dye, 2004; Jacovides et al., 2004; Cho et al., 2010; Ge et al., 2011; Wang et al., 2014). For example, it is shown that $P F$ could be expressed by the exponential or logarithm functions using clearness index (CI) shown as the ratio of SR to the extraterrestrial- horizontal solar radiation (Finch, 2004; Jacovides et al., 2007). Others also show the seasonal or location (sites) differences of $P F$ and these relations with climatic factors such temperature, water vapor, sun elevation and clearness index (Akitsu et al., 2015; Yu et al., 2015).
As for $Q / E$, Dye (2004) derives that $Q / E$ in global PAR shows a representative value of $4.56\left(\mu \mathrm{mol} \mathrm{J^{-1 }}\right)$, however $Q / E$ in diffuse PAR is modelled by the nonlinear function of diffuse ratio $(D R)$ to global PAR. These knowledges derived by precise SR and PAR measurements are precious and important to improve PAR estimation and photosynthesis models. However, the detailed influence on $P F$ and $Q / E$ based on actual observation data related with weather and sky conditions still have not clarified.

In this study, we focus on local weather and various sky conditions, and clarify how sky-conditions influence on $P F, Q / E$, and also the parameters of $D R$ and $C I$ for $P F$ and $Q / E$ models used in previous studies. For this purpose, we examine the dependences of $P F, Q / E$ in global-, diffuse- PARs, $D R$ and $C I$ on sky-conditions factors and compare our results with the existing methods.

\section{MATERIALS AND METHODS}

\subsection{Observation}

We measured the global solar radiation $\left(S R: \mathrm{W} \mathrm{m}^{-2}\right)$ at every 30 seconds and the global and diffuse spectral irradiances with 1-nm intervals (350-1050nm) at even and odd minutes respectively from April of 2005 to January of 2006 in Kyoto, Japan. We used Li-cor pyranometer of LI-200SB (Li-cor, NE, USA) calibrated by CM6B (Kip \& Zonen, Delft, Netherlands) and spectral radiometer of MS-700 (EIKO, Tokyo, Japan) with rotating shadow blade (PRB-100; PREDE, Tokyo, Japan). To derive the factors of sky conditions, we also took whole-sky images at every 2 minutes using commercial-based digital camera (E4500, Nikon, Tokyo, Japan) with fisheye lens (FC-8, Nikon, Tokyo, Japan).

\subsection{PAR fraction and ratio of quanta-to-energy}

These measured global and diffuse spectral irradiances can be converted from energy units (W $\mathrm{m}^{-2} \mathrm{~nm}^{-1}$ ) to quantum units $\left(\mu \mathrm{mol} \mathrm{m} \mathrm{m}^{-2} \mathrm{~s}^{-1} \mathrm{~nm}^{-1}\right)$ by using Planck's constant $\left(6.626 \times 10^{-34} \mathrm{~J} \mathrm{~s}\right)$, the speed of light $\left(3.00 \times 10^{8} \mathrm{~m} \mathrm{~s}^{-1}\right)$ and Avogadro's number 
$\left(6.023 \times 10^{23}\right)$. Then, the global-, diffuse- PAR $\left(P A R_{g}, P A R_{d}: \mathrm{W}\right.$ $\left.\mathrm{m}^{-2}\right)$ and PPFD $\left(P P F D_{g}, P P F D_{d}: \mu \mathrm{mol} \mathrm{m} \mathrm{m}^{-2} \mathrm{~s}^{-1}\right)$ were derived by integrating from 400 to $700 \mathrm{~nm}$. Diffuse PAR and PPFD were furthermore averaged by two data measured in the minute before and after the global spectral irradiance. $S R$ was averaged at 2minutes interval to compare with $P A R_{g}$.

PAR fraction ( $P F$ : unitless), ratio of quanta to energy ( $Q / E$ : $\mu \mathrm{mol}$ $\left.\mathrm{J}^{-1}\right)$ in global and diffuse PAR were calculated as

$$
\begin{gathered}
P F=\frac{P A R_{g}}{S R} \\
Q / E(n)=\frac{P P F D_{n}}{P A R_{n}}
\end{gathered}
$$

where the subscript $n$ is either $\mathrm{g}$ (global) or d (diffuse).

\subsection{Diffuse ratio and clearness index}

To compare the existing methods, we also calculated diffuse PAR ratio (DR: unitless) and clearness index (CI: unitless) as

$$
\begin{gathered}
D R=\frac{P A R_{d}}{P A R_{g}} \\
C I=\frac{S R}{S R_{\text {toa }}} \\
S R_{\text {toa }}=\mathrm{SR}_{0}\left(\frac{\mathrm{r}_{0}}{r}\right)^{2} \sin \theta
\end{gathered}
$$

where $S R_{\text {toa }}$ indicates the extraterrestrial- horizontal solar radiation, $\mathrm{SR}_{0}$ is solar constant of $1367 \mathrm{~W} \mathrm{~m}^{-2},\left(\mathrm{r}_{\mathrm{o}} / r\right)^{2}$ is correction value of the inverse square between $r_{0}$ : the mean distance of earth - sun and $r$ : the distance of earth - sun on observation day and $\theta$ is sun elevation angle (SEA) at observation time.

In case of calculating clearness index for PAR wavelength, we can use $P A R_{g}$ instead of $S R$ and $529 \mathrm{~W} \mathrm{~m}^{-2}$ as solar constant for PAR wavelength $\left(\mathrm{PAR}_{0}\right)$ which is derived from integrating the external terrestrial spectral irradiance from 400-700nm (Thuillier et al., 2003). Clearness PAR index $\left(C I_{p a r}\right)$ can be calculated as follow (eq.6 and 7).

$$
\begin{gathered}
C I_{\text {par }}=\frac{P A R_{g}}{P A R_{\text {toa }}} \\
P A R_{\text {toa }}=\operatorname{PAR}_{0}\left(\frac{\mathrm{r}_{0}}{r}\right)^{2} \sin \theta
\end{gathered}
$$

where $P A R_{\text {toa }}$ is the extraterrestrial- horizontal PAR.

\subsection{Sky conditions factors}

As the numeric data of the sky conditions, we derived cloud cover $(C C)$, sun appearance ratio $(S A)$, and relative whole-sky brightness index $(B I)$ by processing whole-sky image (Yoshimura and Yamashita, 2013).

$\boldsymbol{C C}(\%)$ : Cloud cover is defined as the ratio of the area composed of clouds to the whole-sky area, as a percentage.

$\boldsymbol{S A}(\%)$ : Sun appearance (1) or hiding by clouds (0) on the image indicates the degree to which the sun can be seen and the status of the direct component. Sun appearance/ hiding can be shown as the ratio of sun appearance $(S A)$ for integrating time, i.e. hourly or daily timescale.
$\boldsymbol{B I}(\mathbf{0 - 1})$ : The relative brightness index in the whole-sky image is related to the brightness of the sky and the diffuse component. $B I$ is the average of RGB digital numbers normalized by maximum quantized digital number (8bit: 255) in the hemispherical image area, not including the area classified as the sun.

Additionally, sun elevation angle $\theta$ (SEA) was also used as one of sky-conditions factors.

\section{RESULTS AND DISCUSSIONS}

For analyses, we edited $P F, Q / E(\mathrm{~g}), Q / E(\mathrm{~d}), D R, C I$ with instantaneous values and four sky-conditions factors $(C C, S A, B I$ and SEA) to hourly data. In our analyses, we used totally 2707 samples as hourly data $(6-18,5-19$, and 7-17 hours in spring and autumn, summer, and winter respectively) on 257 days during from $18^{\text {th }}$ of April to $1^{\text {st }}$ of February.

\subsection{Seasonal differences}

To understand the seasonal differences of PAR fraction $(P F)$, quanta to energy ratio $(Q / E)$ in global-, diffuse- PARs, diffuse ratio $(D R)$, and clearness index $(C I)$, we compared monthly averages of $\mathrm{PF}, Q / E(\mathrm{~g}), Q / E(\mathrm{~d}), D R$, and $C I$ with monthly changes of sky conditions factors $(C C, \mathrm{SA}$ and $B I)$ (Figure 1).

Annual average and stander deviation of hourly $P F$ were 0.430 and 0.052 respectively, average of $P F$ was about $7 \%$ lower than comparing with constant value of 0.5 . The monthly differences of $P F$ average were the highest as 0.456 in summer (Jul.) and relatively low as 0.377 and 0.402 in spring (Apr.) and autumn (Nov.). These characteristics were close to the monthly changes of $C C . P F$ at the top of atmosphere is shown as 0.388 by using solar constant of $1365 \mathrm{~W} \mathrm{~m}^{-2}$ and its PAR wavelength of $529 \mathrm{~W}$ $\mathrm{m}^{-2}$. The difference of values between the earth ground and TOA is caused by the absorption of atmosphere. Especially, water vapor and clouds absorb infrared rays well, so the amount of solar radiation including the infrared wavelength band becomes relatively less than PAR.

As for quanta to energy ratio in global and diffuse PARs, annual averages (standard deviation) of hourly $Q / E(\mathrm{~g})$ and $Q / E(\mathrm{~d})$ were $4.558(0.029)$ and $4.500(0.060)$ respectively. The theoretical value of averaging $Q / E$ in PAR wavelength calculated using Planck' constant, the speed of light and is 4.600 . That is, the blue component is relatively larger than the red component in case of $Q / E$ smaller than 4.600. $Q / E(\mathrm{~d})$ was less than $Q / E(\mathrm{~g})$ in this result, that means the diffuse PAR contents much the blue component than the red one. $Q / E(\mathrm{~g})$ was almost same as usual constant values of 4.57 . The monthly differences of $Q / E(\mathrm{~d})$ were also similar to the changes of $C C$ and $D R$, because the monthly changes of $D R$ were also similar to the changes of $C C$.

However, the obvious relationships with sky-conditions factors were not recognized in monthly time-scale. The dependences of $P F, Q / E, D R$ and $C I$ on sky conditions with hourly time-scale in next section.

\subsection{Influences of sky conditions}

To understand the influence of sky conditions on $P F, Q / E, D R$ and $C I$, here, we carried out the multi-regression analysis (MRA) by using four sky-conditions factors (CC, $S A, B I$ and SEA) as explanatory variables. Table 1 and 2 shows the MRA results of partial regression coefficient and standard partial regression coefficient with multiple coefficient of determination $\left(R^{2}\right)$, and single correlation coefficient and partial correlation coefficient respectively.

We compare our results with the existing methods and discuss how $P F, Q / E$, and $D R$ are dependent on sky-conditions factors as follows. 

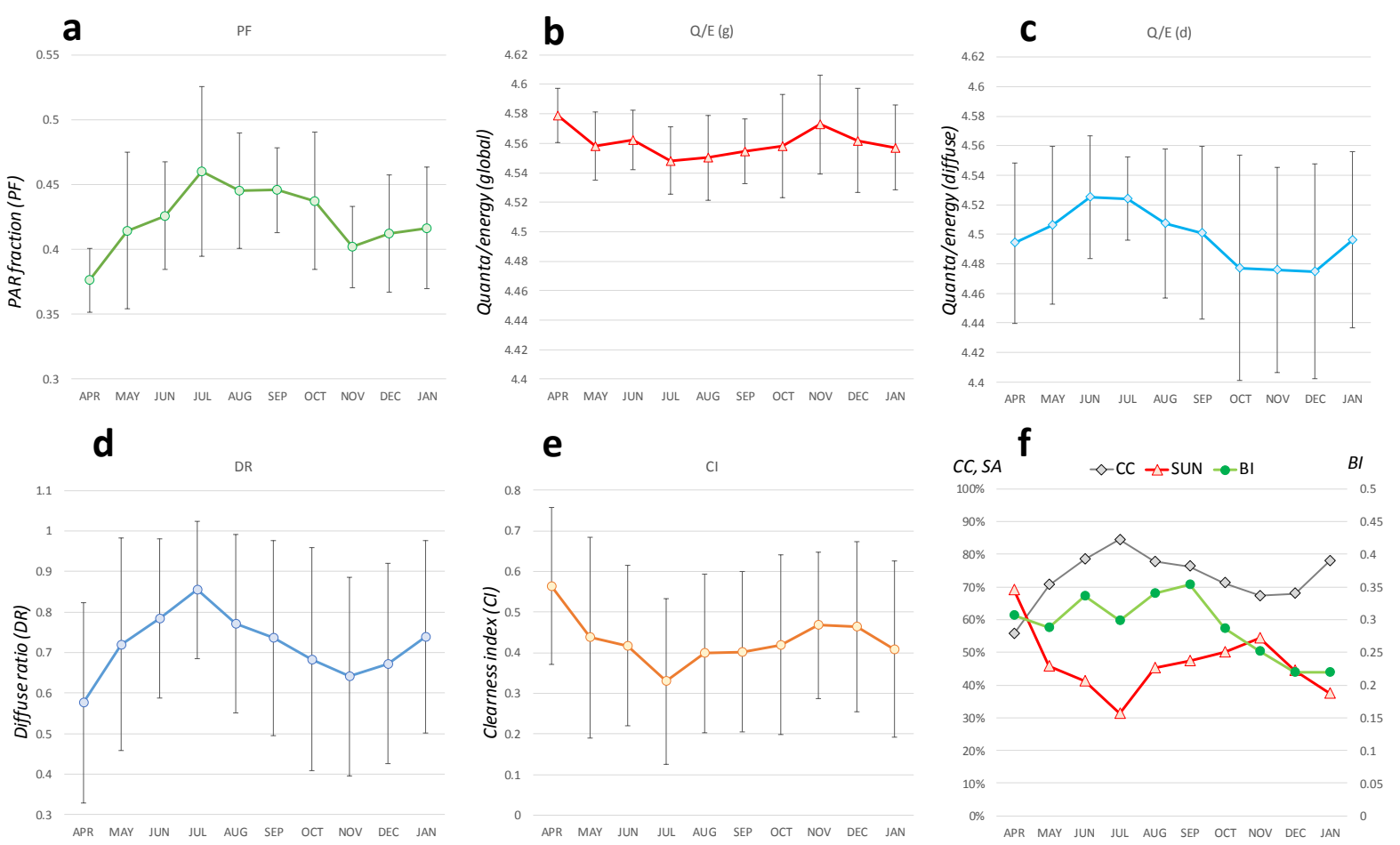

Figure 1. Seasonal changes of (a) PAR fraction: $P F$, (b) quanta to energy ratio in global PAR: $Q / E(\mathrm{~g})$, (c) quanta to energy ratio in diffuse PAR: $Q / E(\mathrm{~d}),(\mathrm{d})$ diffuse ratio: $D R$, (e) clearness index: $C I$, and (f) sky-conditions factors of cloud cover: $C C$, sun appearance ratio: $S A$ and relative brightness: $B I$.

\begin{tabular}{|c|c|c|c|c|c|c|c|}
\hline Variables & & $C C$ & SUN & $B I$ & SEA & intercept & $R^{2}$ \\
\hline \multirow{2}{*}{$P F$} & partial regression coefficient & 0.018 & -0.021 & -0.233 & 0.002 & 0.436 & \multirow{2}{*}{0.375} \\
\hline & standard partial regression coefficient & 0.089 & -0.164 & -0.634 & 0.584 & & \\
\hline \multirow{2}{*}{$Q / E(g)$} & partial regression coefficient & 0.016 & 0.041 & 0.049 & 0.000 & 4.529 & \multirow{2}{*}{0.343} \\
\hline & standard partial regression coefficient & 0.146 & 0.583 & 0.239 & -0.296 & & \\
\hline \multirow{2}{*}{$Q / E(d)$} & partial regression coefficient & 0.206 & -0.008 & 0.075 & & 4.328 & \multirow{2}{*}{0.834} \\
\hline & standard partial regression coefficient & 0.883 & -0.058 & 0.177 & & & \\
\hline \multirow{2}{*}{$D R$} & partial regression coefficient & 0.448 & -0.330 & & 0.000 & 0.557 & \multirow{2}{*}{0.919} \\
\hline & standard partial regression coefficient & 0.474 & -0.556 & & -0.018 & & \\
\hline \multirow{2}{*}{$C I$} & partial regression coefficient & -0.216 & 0.270 & 0.639 & -0.003 & 0.376 & \multirow{2}{*}{0.851} \\
\hline & standard partial regression coefficient & -0.262 & 0.520 & 0.426 & -0.265 & & \\
\hline
\end{tabular}

Table 1. Partial regression coefficient and standard partial regression coefficient with multiple coefficient of determination $\left(R^{2}\right)$ of each $C C, S A, B I$ and SEA for each responsible variables of $P F, Q / E(\mathrm{~g}), Q / E(\mathrm{~d}), D R$ and $C I$. These results are led using only explanatory variables that are considered statistically significant have a $p$-value of $<0.001$.

\begin{tabular}{llrrrr}
\hline Variables & & \multicolumn{1}{c}{$C C$} & \multicolumn{1}{c}{ SUN } & \multicolumn{1}{c}{ BI } & \multicolumn{1}{l}{ SEA } \\
\hline \multirow{2}{*}{$P F$} & single correlation coefficient & 0.302 & -0.443 & -0.342 & 0.102 \\
& partial correlation coefficient & 0.894 & 0.652 & -0.418 & 0.357 \\
$Q / E(g)$ & single correlation coefficient & -0.311 & 0.538 & 0.368 & 0.040 \\
& partial correlation coefficient & 0.909 & 0.730 & -0.272 & 0.140 \\
$Q / E(d)$ & single correlation coefficient & 0.901 & -0.585 & 0.028 & \\
& partial correlation coefficient & 0.919 & 0.717 & -0.229 & \\
$D R$ & single correlation coefficient & 0.874 & -0.902 & & -0.167 \\
& partial correlation coefficient & 0.959 & -0.096 & & -0.058 \\
\multirow{2}{*}{$C I$} & single correlation coefficient & -0.696 & 0.889 & 0.591 & 0.172 \\
& partial correlation coefficient & 0.528 & 0.806 & 0.279 & -0.279 \\
\hline
\end{tabular}

Table 2. Single correlation coefficient and partial correlation coefficient of each $C C, S A, B I$ and SEA for each $P F, Q / E(\mathrm{~g}), Q / E(\mathrm{~d})$, $D R$ and $C I$. 
3.2.1 PAR fraction $(\boldsymbol{P F})$ : According to the result of MRA (Table.1), four sky-conditions factors can explain $P F$ about $37 \%$ $\left(R^{2}: 0.375\right)$. In previous studies (Finch, 2004; Jacovides et al., 2007, Yu et al.,2015), $P F$ models have been expressed by the function of clearness index $(C I)$. Figure 2 show the relations with $P F$ and $\mathrm{Cl}$, we can find the same result shown as the logarithm functions $(P F=-0.054 \ln (C I)+0.371)$ with $R^{2}: 0.642$. This function means that when $C I=1.0$, i.e. $P F$ at TOA, $P F$ is 0.371 . This value is difference of about $1.7 \%$ by comparing with 0.388 calculated from solar constant.

Furthermore, we added " $-0.054 \ln (C I)$ " as explanatory variable to four factors of sky-conditions in the multi-regression analysis. The result of $R^{2}$ was 0.749 and improved about $10 \%$ than the existing $P F$ model by addition of sky conditions factors.

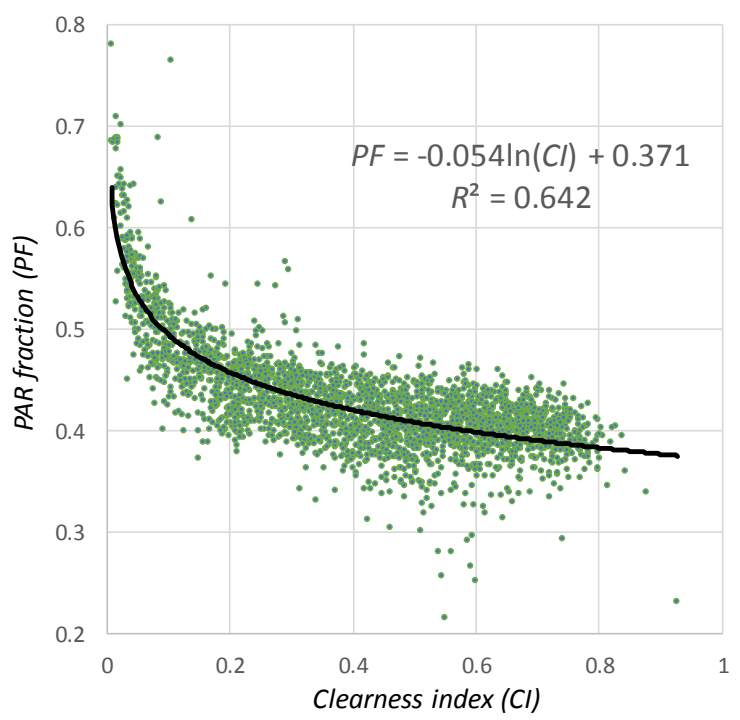

Figure 2. The relationship between $P F$ and $C I$

3.2.2 Quanta to energy ratio in global PAR: $Q / E(\mathrm{~g})$ and diffuse PAR: $\boldsymbol{Q} / \boldsymbol{E}(\mathbf{d})$ : As for the existing method (Dye., 2004), $Q / E(\mathrm{~g})$ and $Q / E(\mathrm{~d})$ are modelled by the linear and non-linear functions of $D R$. Figure 3 shows the relationships between $Q / E(\mathrm{~g})$, (d) and $D R$. The approximation functions shown in graphs were derived by following Dye's models. $R^{2} \mathrm{~s}$ of $Q / E(\mathrm{~g})$ and $Q / E(\mathrm{~d})$ were 0.334 and 0.694 respectively.

Comparing with the results of MRA, $Q / E(\mathrm{~g})$ is explained by four factors of sky-conditions with $R^{2}: 0.343$ (Table1) which is almost same result with using $D R$. As for $Q / E(\mathrm{~d})$, there are strong positive correlation with $C C$ (single correlation coefficient (s.c.c): 0.901) (Table2). $Q / E(\mathrm{~d})$ can be explained by three variables of $C C, S A$ and $B I$ with high $R^{2}: 0.834$ (Table1). This is higher than Dye's model using $D R$.

3.2.3 Diffuse ratio $(D R): D R$ have also been modelled by an $\mathrm{n}^{\text {th }}$ - degree function using clearness index $(C I)$ in previous studies (e.g. Jacovides et al., 2007 and 2010). Here, we used clearness index for PAR wavelength $\left(C I_{\mathrm{par}}\right)$. Figure 4 shows the

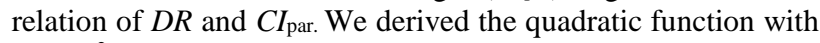
high $\mathrm{R}^{2}(0.852)$.

As for the relations with sky conditions factors, $D R$ had strong positive correlation with $C C$ (s.c.c: 0.874 ) and strong negative correlation with SA (s.c.c: -0.902) (Table2), but almost no correlation with $B I$. As the result of MRA, $D R$ can be explained by three variables of sky conditions with very high $\mathrm{R}^{2}(0.919)$ (Table1). This is also higher than the existing model using $C I$.
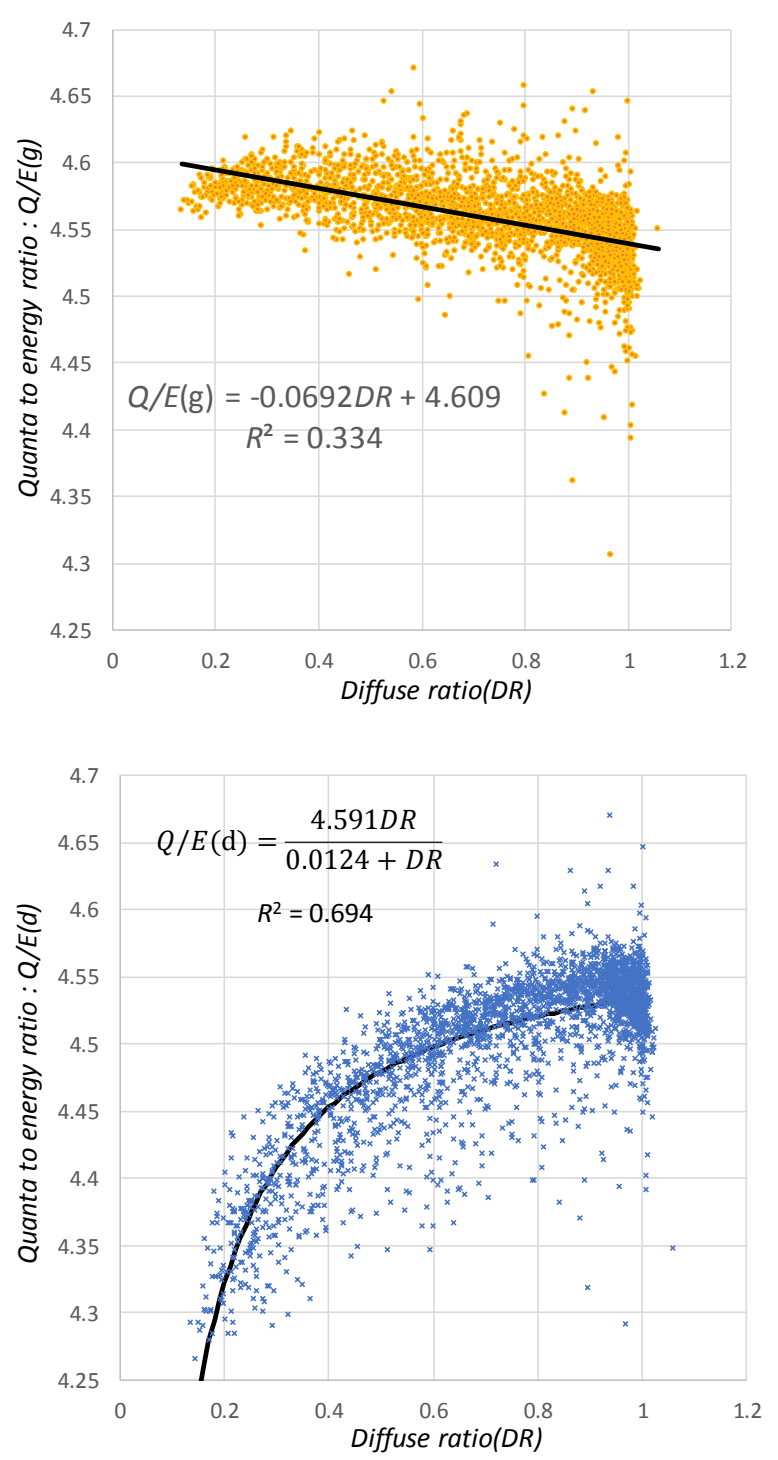

Figure 3 The relationships between $Q / E(\mathrm{~g})$ and $D R$ (upper), and $Q / E(\mathrm{~d})$ and $D R$ (lower).

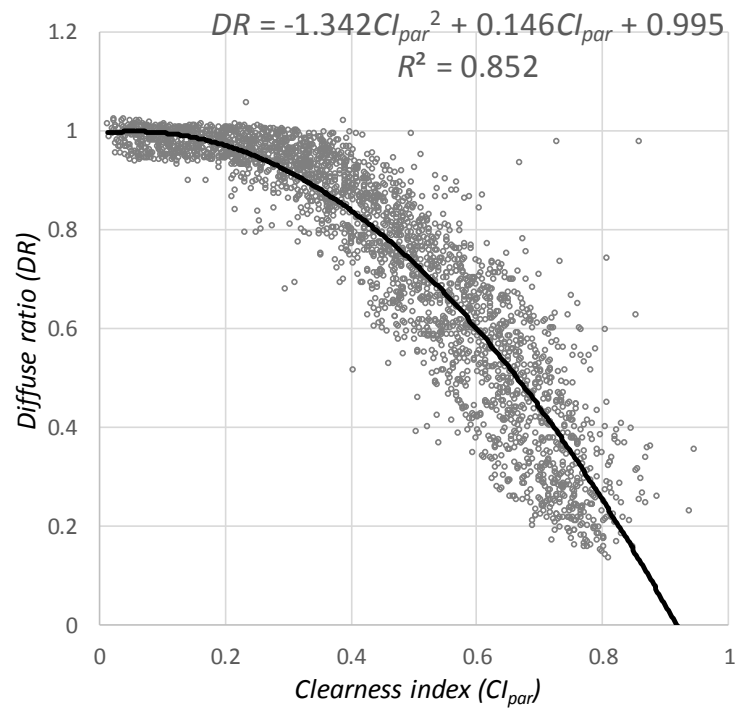

Figure 4 The relationship between $D R$ and $C I$. 
3.2.4 Clearness index $(C I): C I$ has been used to estimate $P F$ and $D R$ in many previous studies. According to our results of MRA, it was clarified that $C I$ can be explained by four skyconditions factors with $R^{2}: 0.851$ (Table1). Especially, $C I$ has the strong positive correlation with SA (s.c.c: 0.889) (Table2). Thus, in case of that there is no data of SR, it is possible to estimate $P F$ and $D R$ by using these sky-conditions factors.

\section{CONCLUSION}

Through this study, we could clarify the detailed influence of sky conditions factors on the estimation of PPFD by $P F, Q / E$ in global and diffuse PAR, and $D R$ in hourly timescale. These knowledges would be contributed to improve photosynthetic models at community scale with short-time scale for local agricultural ecosystem. As our future works, we will develop the PPFD estimation model based on the sky-conditions variables derived from whole-sky images and validate its accuracy by comparing with existing estimation models.

\section{ACKNOWLEDGEMENTS}

This research was partially supported by a Grant-in-Aid for scientific research (No. 16310017) from the Ministry of Education, Science and Culture, Japan.

\section{REFERENCES}

Akitsu, T., Kume, A., Hirose, Y., Ijima, O., Nasahara, K.N., 2015 On the stability of radiometric ratios of photosynthetically active radiation to global solar radiation in Tsukuba, Japan. Agric. For. Meteorol. 209, 59-68. https://doi.org/10.1016/j.agrformet.2015.04.026

Cho, J., Oki, T., Yeh, P.J.F., Kanae, S., Kim, W., 2010. The effect of estimated PAR uncertainties on the physiological processes of biosphere models. Ecol. Modell. 221, 1575-1578. https://doi.org/10.1016/j.ecolmodel.2010.03.009

Dye, D.G., 2004. Spectral composition and quanta-to-energy ratio of diffuse photosynthetically active radiation under diverse cloud conditions. J. Geophys. Res. D Atmos. 109, 1-12. https://doi.org/10.1029/2003JD004251

Finch, D.A., Bailey, W.G., McArthur, L.J.B., Nasitwitwi, M., 2004. Photosynthetically active radiation regimes in a southern African savanna environment. Agric. For. Meteorol. 122, 229238. https://doi.org/10.1016/j.agrformet.2003.09.015

Ge, S., Smith, R.G., Jacovides, C.P., Kramer, M.G., Carruthers, R.I., 2011. Dynamics of photosynthetic photon flux density (PPFD) and estimates in coastal northern California. Theor. Appl. Climatol. 105, 107-118. https://doi.org/10.1007/s00704-0100368-6

Jacovides, C.P., Timvios, F.S., Papaioannou, G., Asimakopoulos, D.N., Theofilou, C.M., 2004. Ratio of PAR to broadband solar radiation measured in Cyprus. Agric. For. Meteorol. 121, 135140. https://doi.org/10.1016/j.agrformet.2003.10.001

Jacovides, C.P., Tymvios, F.S., Assimakopoulos, V.D., Kaltsounides, N.A., 2007. The dependence of global and diffuse PAR radiation components on sky conditions at Athens, Greece. Agric. For. Meteorol. 143, 277-287. https://doi.org/10.1016/j.agrformet.2007.01.004
Jacovides, C.P., Boland, J., Asimakopoulos, D.N., Kaltsounides, N.A., 2010. Comparing diffuse radiation models with one predictor for partitioning incident PAR radiation into its diffuse component in the eastern Mediterranean basin. Renew. Energy 35, 1820-1827. https://doi.org/10.1016/j.renene.2009.11.015

Monteith, J. L., 1977. Climate and the efficiency of crop production in Britain. Philos. Trans. R. Soc. London. B, Biol. Sci. 281, 277-294.

McCree, K. J. ,1972. Test of current definitions of photosynthetically active radiation against leaf photosynthesis data, Agric. Meteorol., 10, 443-453.

Ohmura, A., Dutton, E.G., Forgan, B., Fröhlich, C., Gilgen, H., Hegner, H., Heimo, A., König-Langlo, G., McArthur, B., Müller, G., Philipona, R., Pinker, R., Whitlock, C.H., Dehne, K., Wild, M., 1998. Baseline Surface Radiation Network (BSRN/WCRP): New Precision Radiometry for Climate Research. Bull. Am. Meteorol. Soc. 79, 2115-2136. https://doi.org/10.1175/15200477(1998)079<2115:BSRNBW>2.0.CO;2

Thuillier, G., Hers , M., Simon, P.C., Labs, D., Mandel, H., Gillotay, D., 2003. Observation of the solar spectral irradiance from $200 \mathrm{~nm}$ to $870 \mathrm{~nm}$ during the ATLAS 1 and ATLAS 2 missions by the SOLSPEC spectrometer. Metrologia 35, 689695. https://doi.org/10.1088/0026-1394/35/4/79

Wang, L., Gong, W., Li, J., Ma, Y., Hu, B., 2014. Empirical studies of cloud effects on ultraviolet radiation in Central China. Int. J. Climatol. 34, 2218-2228. https://doi.org/10.1002/joc.3832

Yoshimura, M., Yamashita, M., 2013. Contribution of GroundBased Cloud Observation to Satellite-Based Cloud Discrimination. J. Environ. Sci. Eng. A 2, 487-493.

Yu, X., Wu, Z., Jiang, W., Guo, X., 2015. Predicting daily photosynthetically active radiation from global solar radiation in the Contiguous United States. Energy Convers. Manag. 89, 7182. https://doi.org/10.1016/j.enconman.2014.09.038

Zhang, X., Zhang, Y., Zhoub, Y., 2000. Measuring and modelling photosynthetically active radiation in Tibet Plateau during April-October. Agric. For. Meteorol. 102, 207-212. https://doi.org/10.1016/S0168-1923(00)00093-9 